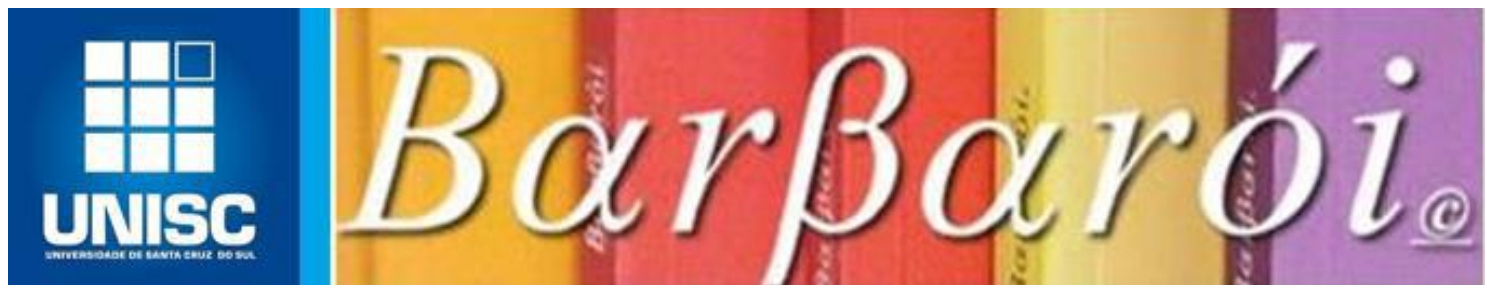

\title{
PELOTAS-RS PELAS SUAS MARGENS: A PATRIMONIALIZAÇÃO COMO EXPRESSÃO DAS MÚLTIPLAS FORMAS DE HABITAR A CIDADE
}

\author{
DOI: http://dx.doi.org/10.17058/barbaroi.v0i0.14593
}

\author{
Francisco Pereira Neto \\ Universidade Federal de Pelotas - UFPEL - Brasil \\ Flavia Rieth \\ Universidade Federal de Pelotas - UFPEL - Brasil \\ Louise Alfonso \\ Universidade de Santa Cruz do Sul - UNISC - Brasil
}

\section{Resumo}

A proposta do artigo é localizar este trabalho dentro de uma antropologia urbana que interpreta a cidade não como uma dimensão externa aos habitantes, como uma unidade política e administrativa, mas perceber a cidade como um objeto virtual, constituída por disputas de narrativas sobre seus territórios. Para tratar este tema, partimos da tensão com a cidade normativa através de uma reflexão sobre suas margens. Pensando a agência das narrativas de grupos subalternos a partir de processos de patrimonialização de bens culturais da cidade de Pelotas/RS. Mais do que se conformar à perspectiva oficial sobre patrimônio, o texto propõe uma ressignificação desse mesmo conceito. Na cidade de Pelotas aquelas narrativas oficiais que desvinculam a opulência do período da produção do charque e inviabilizam o passado da escravidão, são questionadas por diferentes grupos que se apropriam do conceito de patrimônio. Comunidades negras passam a reivindicar sua presença na constituição do centro histórico e de outros territórios da cidade, o que tem ocasionado tensões no uso destes bens. Os efeitos dessa controvérsia acabam influenciando as definições do direito à cidade, que deixa de ser atribuição exclusiva das pressões do mercado criado pela expansão imobiliária. Este estudo nos possibilita perceber uma importante ação na definição dos territórios da cidade, que passa por uma dialética entre margem e centro, dimensão relevante para definir a própria concepção de centro urbano em disputa por modos de habitar a cidade.

Palavras chave: cidade, margens, patrimônio cultural. 


\section{Introdução}

A proposta é de localizar este trabalho dentro de uma antropologia urbana nos termos de Agier (2015) que interpreta a cidade não como uma dimensão externa aos habitantes, globalizante e que pode ser analisada na sua totalidade, mas perceber a cidade como um objeto virtual, constituída por disputas de narrativas sobre seus territórios. Para tratar este tema, partimos da tensão com a cidade normativa através de uma reflexão sobre suas margens. Pensando a agência das narrativas de grupos subalternos a partir de processos de patrimonialização.

A importância de um conceito oficial de patrimônio se consolida na atualidade pelo tombamento do conjunto histórico de Pelotas e registro da região doceira de Pelotas e Pelotas antiga que ocorreram em maio de 2018 pelo Instituo do Patrimônio Histórico e Artístico Nacional (IPHAN). Desde a década de 1950, com um levantamento de mais de mil imóveis inventariados, com legislação municipal específica sobre o tema desde a década de 1980, com ações do Programa Monumenta, constantes atividades junto à comunidade sobre um conceito de patrimônio que se queria fortalecer, sobre a importância da preservação e realização de evento anual denominado Dia do Patrimônio ganhador prêmio Rodrigo Melo Franco, ações que demonstram a centralidade do conceito de Patrimônio na definição de uma perspectiva de cidade.

As pesquisas vinculadas ao Grupo de Estudos Etnográficos Urbanos (GEEUR) da Universidade Federal de Pelotas (UFPEL) têm evidenciado um processo importante de disputa de narrativas a partir deste conceito de patrimônio reforçado por décadas. Ocorre que grupos inicialmente invisibilizados nas narrativas oficiais da cidade passam a demarcar o reconhecimento de suas práticas e saberes como constituidores da história de Pelotas. Mais que se conformar à perspectiva estabelecida sobre patrimônio, propõem uma ressignificação desse mesmo conceito.

Aquelas narrativas oficiais que desvinculam o sal do açúcar, a opulência do período charqueador invisibilizando o passado da escravidão, são questionadas por diferentes grupos que se apropriam do patrimônio. Comunidades negras passam a reivindicar sua presença na constituição do centro histórico e da cidade, o que tem ocasionado tensões no uso destes bens. Também com a proposta de transferência do centro administrativo da cidade para a área do Passo dos Negros, estimulando a especulação imobiliária e ocasionando a remoção de moradoras/es, a patrimonialização de bens relacionados ao sítio charqueador vem sendo reivindicada para garantir a permanência destas comunidades em seus territórios tradicionais. Estes estudos nos possibilitam perceber uma importante ação na definição dos territórios da Barbarói, Santa Cruz do Sul, Edição Especial n.54, p.<63-75>, jul./dez. 2019 
cidade, que passa por uma dialética entre margem e centro, dimensão relevante para definir a própria concepção de centro urbano em disputa por modos de habitar a cidade.

\section{Cidade em transformação}

As considerações sobre um poder contemporâneo constituído pela força de sistemas, ou seja, modelos de fazer a vida que se pautam em "competências", "especialidades" que normatizam o que é realidade e o que é mera especulação da imaginação (nestes termos, o domínio do irreal), não determinam a inexistência do que "transborda" às premissas políticas e epistêmicas da norma. Normalmente, esses excessos da realidade são tratados através da lógica do desvio, a qual diz que o que sobra ao modelo não tem força de realização e deve ser colocado à parte, como coisa (matéria, ideia) desordenada e, por isso, negativa. No caso do tema das definições sobre o espaço urbano, o que não cabe no princípio funcionalista, o que "não funciona", deve ser descartado como anomalia, como impróprio para definir a totalidade do que se define como cidade.

Nossa proposta é refutar essa premissa dizendo, junto com outros autores da antropologia como Agier (2015) e Magnani (2012), que o que nos interessa na definição da cidade são suas margens, justamente aquele espaço em que a conformação e as propriedades do território estão sendo disputadas. Essa prioridade está baseada na definição de que a cidade é o "movimento de fazer a cidade" (AGIER, 2015), uma vez que a cidade é um "objeto virtual" que é ultrapassado pelo urbano, fenômeno que caracteriza a sociedade contemporânea (LEFEBVRE, 2001). Portanto, as disputas pela ocupação dos espaços da cidade, as formas materiais que essas ações produzem - como os condomínios fechados com seus espaços de geometria funcional perfeita; as favelas e vilas com o espaço constituído por suas moradias frágeis, improvisadas e provisórias, dizem muito sobre a realidade da cidade. São nestes espaços de fronteira onde se constituem as referências ideais e materiais que motivam a diversidade dos modos de habitar a cidade. Para alcançar essa dimensão criativa da cidade, é fundamental estar atento ao que se pensa, mas também, em igual importância, ao que se faz. Assim, a observação das margens, das periferias das cidades, das fronteiras que os espaços urbanos nos apresentam é o método de uma antropologia urbana preocupada em expressar a dimensão política de suas opções epistemológicas:

Para introduzir esta reflexão, eu devo dizer logo de saída que o vínculo que será estabelecido aqui entre etnografia das margens e antropologia da cidade não pretende reproduzir a oposição radical ou mesmo 'ontológica' entre a marginalidade e a centralidade em si. Muito ao contrário, eu pretendo descrever uma dinâmica, uma dialética, uma relação necessária e, por fim, certa continuidade entre uma e outra. Mais profundamente, eu desejo implementar um método que permita pensar a 
universalidade da cidade fora de qualquer pretensão normativa, ou seja, segundo uma concepção ao mesmo tempo epistemológica e política. Baseada em pesquisa etnográfica urbana, esta concepção defende a ideia de uma construção/ desconstrução de seu objeto "cidade", rejeitando qualquer definição a priori da mesma enquanto ferramenta analítica. A questão seria antes: o que faz e desfaz a cidade permanentemente? Ela conduz à divulgação de processos e portanto à política que impulsiona o movimento necessário à sua existência, às suas reprodução e transformação. (AGIER, 2015, p. 483)

Essa concepção geral da constituição de uma cidade no seu aspecto epistemológico e político interfere nas múltiplas definições das cidades. Em Pelotas/RS, a partir de alguns dos projetos de pesquisa e extensão do Grupo de Estudos Etnográficos Urbanos (GEEUR) da Universidade Federal de Pelotas (UFPEL), tornou-se evidente que o tema do Patrimônio Cultural é um conceito em disputa pela sua centralidade na configuração normativa do que é a cidade. Como Pelotas é definida por seu forte viés "cultural", há grande interesse de diferentes grupos em influenciar uma narrativa sobre a cidade que expresse as expectativas que possuem sobre o que é a cidade e as prioridades que a definem.

Este texto pretende, a partir da análise da narrativa distintiva de Pelotas, que ressalta um passado de opulência, compreender o apagamento da história e cultura do negro neste processo de constituição da cidade que se atualiza. Esta narrativa selecionada, diz respeito a uma determinada temporalidade e elege a perspectiva de um grupo social específico para qualificar os fatos sociais como bens culturais que produzem prestígio. A cidade assim, não é pensada em sua heterogeneidade. A proposição que se encaminha busca perceber a cidade como um bem cultural que se reinventa constantemente, enfatizando as formas como ela é vivida. São as práticas do habitar, atos que se realizam no cotidiano e que o tempo adensa, que qualificam no urbano o que será legitimado como de valor cultural.

Nestes termos, acompanhando a reflexão de De Meneses (2006) atenta-se para as dimensões de artefatos, campos de força e significações. Dimensões que se articulam na medida em que "a cidade é coisa feita, fabricada" (2006, p. 36) por práticas sociais que atribuem sentido ao espaço, a cidade se constrói como um campo de forças

\footnotetext{
(...) são nas forças que geram os interesses e nos conflitos que podem opô-los uns aos outros e nos jogos variados de proposição, imposição ou negociação que encontraremos as chaves pelas quais certos atributos geométricos e físico-quimicos (os únicos imanentes) das coisas permitem sua mobilização a serviço do sentido. Sem as práticas sociais, não há significados sociais. Mas também não há significados sociais sem vetores materiais (DE MENESES, 2006, p. 37).
}

Assim, o viver na/da cidade abarca diferentes historicidades, o que nos permite pensála em transformação. A paisagem urbana é heterogênea porque nela coexistem diversas temporalidades inscritas na sua materialidade, bem como por abarcar diferentes visões de mundo e de valores das pessoas que a habitam.

Barbarói, Santa Cruz do Sul, Edição Especial n.54, p.<63-75>, jul./dez. 2019 
Os exemplos do Passo dos Negros e da Região Doceira, operam de maneiras diferentes, porém trazem elementos interessantes para se pensar processos de inclusão e exclusão sociais, pela seleção (ou não) de referências culturais nesta narrativa da tradição. No Passo dos Negros é marcante a exclusão da memória e da história da escravidão, bem como da funcionalidade daquele espaço como entreposto comercial e fiscal no passado, que reflete, inclusive, em um processo de abandono da localidade pela ausência do atendimento dos serviços de infraestrutura urbana no presente. Quanto ao reconhecimento de Pelotas e Pelotas Antiga como Região Doceira, a partir de sua valorização e patrimonialização, observa-se o tensionamento do processo de disseminação de um saber fazer doceiro, que abarca a cidade como um todo, em face a busca das origens da marca cultural doces de Pelotas.

\section{Uma história de distinção e opulência}

Pelotas trata-se de uma cidade localizada no extremo sul do estado do Rio Grande do Sul, às margens da Lagoa dos Patos, à $60 \mathrm{~km}$ do Porto de Rio Grande e aproximadamente $130 \mathrm{~km}$ do Uruguai. Configura-se como um dos primeiros centros urbanos do estado, localizada em uma região eminentemente rural em razão da atividade da pecuária extensiva no pampa Sul-Rio-Grandense, o que destaca sua presença em uma negociação entre rural e urbano.

A referência de distinção se inicia com a época das charqueadas, no século XIX. Estas travam-se de estabelecimentos voltados para a produção do charque, carne salgada utilizada para a alimentação de pessoas escravizadas, exportada para todo o Brasil. As charqueadas em Pelotas se utilizaram de mão-de-obra escravizada. A narrativa oficial ressalta a história de grandes famílias charqueadoras, seus modos de vida, compreendidos como uma "civilização urbana".

\footnotetext{
Trata-se de uma história marcada pela presença de grandes homens e a riqueza do Charque, que valoriza como temporalidades a época das charqueadas que se atualiza no presente, por intermédio do tombamento dos casarões do centro histórico da cidade, que privilegia uma determinada história, classe social, gênero e etnia. (ALFONSO, RIETH, 2016, p. 134)
}

Esta narrativa respaldou, ao longo do tempo, as políticas públicas de patrimonialização, em especial de bens edificados da cidade, com a constituição de um centro histórico e reconhecimento de alguns elementos do que se considerou um sítio charqueador. $\mathrm{O}$ turismo também se vale desta narrativa oficial como atrativo para a constituição e formatação de atrativos turísticos na cidade. Um exemplo é o roteiro histórico que prevê a visitação aos casarões do centro histórico, Mercado Público, Praça Coronel Pedro Osório, Biblioteca 
Pública, teatros e docerias, para acessar esse modo de vida da elite local, daquele período. Ressalta uma colonização europeia, em especial a portuguesa, que se notabilizou por este modo de vida sofisticado e urbano, invisibilizando as comunidades negras e deixando em um segundo plano a dimensão rural da cidade.

Com a redemocratização do país e o fortalecimento dos movimentos socais, narrativas contra discursivas (SAID, 1990) ganham corpo e passam a contar novas histórias sobre estas referências culturais. As comunidades negras, em especial vinculadas ao movimento negro, em rede com a Universidade, o IPHAN, sindicatos, passam a reivindicar sua inclusão nesta história da cidade, contando outras narrativas sobre estes mesmos bens já reconhecidos. Bem como, exigindo a valorização de outros bens até então invisibilizados, em uma tentativa de pensar esta história a partir de uma ideia de sujeitos detentores de saberes que conformam uma comunidade. Também comunidades rurais entram na cena ao se pensar uma equiparação de saberes e o intercâmbio entre o rural e o urbano. Para exemplificar estes processos reivindicatórios trazemos como exemplo a patrimonialização dos Doces de Pelotas e do território do Passo dos Negros.

\section{O açúcar e o sal}

O processo de registro das tradições doceiras de Pelotas e Pelotas antiga (Turuçu, Morro Redondo, São Lourenço do Sul e Capão do Leão, cidades no entorno de Pelotas) remonta ao ano de 2006, quando se iniciou o trabalho de campo para a elaboração da solicitação de registro deste bem cultural como patrimônio imaterial brasileiro. Na época utilizou-se a metodologia de rede, tanto para a indicação dos/as interlocutores/as, como no ingresso em campo. Optou-se por entrar a partir da zona rural, da zona urbana, das docerias, de associações de doceiras e da FENADOCE (Festa Nacional do Doce), no sentido de identificar as/os detentoras/es deste saber de forma a documentar, valorizar e propor ações de salvaguarda do Bem inventariado. Esta tradição se desdobra entre os doces finos de origem portuguesa, vinculados ao meio urbano, e os doces coloniais, vinculados ao rural, a partir dos empreendimentos de imigração italiana, alemã, pomerana e francesa. Uma das ideias do inventário era a discussão da história de Pelotas a partir dos doces.

Neste sentido o trabalho de Marilia Kosby (2007), integrante da equipe, é revelador pois diante da pergunta: Qual a contribuição negra? A resposta recorrente de que as/os negras/os só mexeram o tacho passa a ser questionada. Diante da resposta de uma trabalhadora doméstica, participante de uma religião de matriz africana, mostrou-se a presença dos doces nas terreiras de Pelotas. Cabe destacar, que a região de Pelotas se trata da Barbarói, Santa Cruz do Sul, Edição Especial n.54, p.<63-75>,jul./dez. 2019 
segunda do Brasil em número de casas de religiões de matriz africana. A partir desta fala, as respostas e as/os interlocutores/as se alteram. "Nós cultuamos todas as doçuras", "em toda terreira tem sempre uma doceira", são exemplos de respostas que mostraram estes doces passaram a fazer parte da cosmologia das religiões, sendo ofertados para os orixás. A tradição doceira de Pelotas se cruza assim, com a cosmologia de matriz africana, a partir da classificação dos orixás do mel e dos orixás de dendê.

Da mesma forma, a tradição dos doces coloniais se configura como uma presença marcante na história da cidade, a partir da Serra dos Tapes. Esta região é reconhecida por sua "vocação" de fruticultura. As antigas chácaras de charqueadores, transformadas em lotes de imigração, trouxeram a presença de alemães, pomeranos, italianos, franceses, entre outras nacionalidades, para compor a história da cidade e constituir um novo modo de vida camponês.

Inicialmente na história da cidade, o protagonismo não era do doce, mas do sal para a produção do charque. O açúcar, produzido no Nordeste, aparece no intercâmbio com o sal. Os mesmos navios que levavam o charque para o nordeste do Brasil, traziam o açúcar para o Rio Grande do Sul. Com a crise da indústria saladeril, no início do século XX, essa relação de complementaridade se inverte e a comercialização dos doces passou a ser uma forma de sustento de muitas famílias pelotenses.

O inventário também foi alvo de disputas na cidade, afinal sua narrativa também constrói essa cidade virtual. A presença destes doces finos nas terreiras é questionada, como se estes não fossem os "autênticos" doces de Pelotas. O acesso às linhagens de doceiras negras e identificação destas doceiras ainda continua incipiente. A equiparação das duas tradições, doces coloniais e doces finos, também gera conflitos pois se construiu uma ideia de que os "verdadeiros" doces de Pelotas são os doces finos.

No mesmo período em que o registro de patrimônio material estava em processo, em paralelo, tem-se o processo da indicação geográfica de certificação de procedência dos doces, encaminhado pela Câmara de Dirigentes Lojistas, Prefeitura Municipal de Pelotas e pelo SEBRAE. Evidencia-se que a indicação funciona na lógica do mercado, regulamentado pela vigilância sanitária, que exige uma cozinha industrial, azulejada, não permite o uso de tacho de cobre, de colher de pau, a secagem do doce não pode ser ao ar livre, mas em estufa, entre outras normas. Estes procedimentos excluem muitos/as dos/as detentores/as deste saber.

Neste ano de 2018, se efetiva o registro dos doces como patrimônio imaterial brasileiro, em que o IPHAN (2018b) acompanha o dossiê que respalda este processo. O parecer final do IPHAN, produzido pela conselheira Marcia Santana, votado em maio do Barbarói, Santa Cruz do Sul, Edição Especial n.54, p.<63-75>, jul./dez. 2019 
corrente ano, busca articular o registro dos doces e o tombamento dos bens edificados. Ela evidencia uma Pelotas negra em uma intima relação entre o urbano e o rural, dando a mesma visibilidade às duas tradições doceiras e reconhecendo diferentes linhagens de doceiras na região. Todavia, a aceitação deste parecer não foi unanime na cidade, representando uma perspectiva muito presente de desvincular o sal do açúcar e invisibilizar a experiência escravista em Pelotas.

A mesma rejeição pode ser identificada quando a discussão do sítio charqueador passa a ser uma questão, dentro do processo de tombamento do Conjunto Histórico de Pelotas. O processo de tombamento recomenda a patrimonilização de imóveis, em sua maioria, localizados no centro histórico de Pelotas, relacionados às famílias da elite local. A parecerista, aponta em sua avaliação, outros elementos além daqueles valorizados pelo processo. Dentre eles destacamos o Passo dos Negros.

\section{Passo dos Negros: um território negro invisibilizado}

O Passo dos Negros é uma região onde localizou-se o antigo porto de Pelotas, local de taxação de mercadorias, por onde entravam o açúcar, as tropas e pessoas escravizadas em Pelotas. Está localizado às margens do Canal São Gonçalo, que se tratava de uma importante via fluvial que ligava Pelotas ao porto marítimo de Rio Grande. Naquela região, também se localizava uma importante charqueada. Posteriormente ao período do charque, sediou um dos maiores engenhos de arroz da América Latina.

Com a construção do centro da cidade longe das charqueadas, no início do século XVIII, reforça-se uma separação entre uma cidade para habitar e uma cidade do trabalho. As justificativas estavam relacionadas ao cheiro fétido e à insalubridade das charqueadas. Falase, inclusive, da cor vermelha das águas do canal que recebia os dejetos das charqueadas, denominando o São Gonçalo de rio de sangue. No ciclo do arroz, a construção de uma vila operária do Engenho do Coronel Pedro Osório respalda um território de habitação de muitos trabalhadores e suas famílias. Nos mapas oficiais da cidade, desde 1815, este território aparece como um vazio urbano. Mesmo os mapas de 2011, que apontam para áreas de ocupações irregulares das margens do São Gonçalo, não mostram essas gerações de trabalhadoras/es que ali habitam.

No ano de 2014, se inicia uma pesquisa naquela região buscando identificar as narrativas sobre um passado de escravidão na cidade. Identifica-se um Passo dos Negros múltiplo, formado por diferentes grupos que chegam àquela região em temporalidades diversas. Um grupo mais antigo, vinculados ao passado de escravidão. Outro grupo, diz Barbarói, Santa Cruz do Sul, Edição Especial n.54, p.<63-75>, jul./dez. 2019 
respeito aos trabalhadores do engenho e suas famílias. Uma ocupação mais recente, que demonstra um fluxo constante de trabalhadores/as que habitam as periferias de Pelotas. Também se encontram na região descendentes de tropeiros e famílias da elite local que habitam propriedades às margens do São Gonçalo, território de antigas charqueadas.

Esses diferentes grupos elencam uma gama de elementos representativos para aquela localidade, que não necessariamente estavam vinculados à época das charqueadas, temporalidade destacada na história da cidade. $\mathrm{O}$ elemento mais antigo mencionado trata-se da ponte dos dois arcos, construída de tijolos por mão-de-obra escravizada. Também foram mencionadas duas figueiras como significativas. A primeira seria a figueira da noiva, onde habita a mulher de branco abandonada no altar, que assombra as noites do Passo. A segunda traz sombra para a ponte e seus frequentadores, alguns netos de pessoas escravizadas que vão tomar chimarrão aos domingos e contar causos. Ambas as figueiras, são depositórios de oferendas de casas de religiões de matriz africana. Cabe ressaltar que as figueiras substituem os baobás da África na cosmologia destas religiões. Junto à figueira e, passando por cima da ponte, está o caminho das tropas, antigo percurso dos animais por dentro da cidade até os matadouros. Por fim, e mais representativo para a comunidade está o Engenho. Sua edificação conta com prédio central, a antiga escola, uma parte da antiga vila operária e o campo de futebol do Osório futebol Clube, o que para nós constitui-se no conjunto do Engenho.

As transformações da cidade com a constituição do centro histórico e crescimento urbano localizou muitas disputas naquela área. A construção do shopping de Pelotas e o deslocamento do fórum, do tribunal de contas, da delegacia do trabalho, da justiça eleitoral, dentre outros órgãos do judiciário, somados a novos empreendimentos imobiliários, acirrou um processo de expulsão de comunidades daquela região, desconsiderando qualquer referência do habitar destas populações. A ampliação deste processo previa implantação de três empreendimentos imobiliários naquela localidade. O primeiro, já efetivado trata-se de um condomínio de casas de classe média alta, cercado por um muro verde que antes parecia tão marcado na paisagem, mas que atualmente passa desapercebido pois as mansões já ultrapassaram seu tamanho. Em construção, encontra-se o segundo empreendimento, sem muros, que ressalta uma narrativa de cidade inclusiva, aberta, segura, mas que amplia os processos de remoção destas comunidades.

Os responsáveis pelos empreendimentos imobiliários não reconhecem a presença destas/es moradores. A construção desses condomínios apenas é possível pois são constantes as alterações no Plano diretor da cidade, que reforça esta ideia de um vazio urbano naquele 
local. O projeto ainda prevê a ocupação do engenho e a duplicação da estrada do engenho, onde localizam-se muitas ocupações de pescadores, também em processos de remoção.

Durante a construção do condomínio murado, a obra de instalação da tubulação sanitária quase danificou a ponte dos dois arcos, que foi defendida por um dos moradores que ocupam o antigo corredor das tropas. Este morador que solicitou à equipe do projeto "Margens: grupos em processos de exclusão e suas formas de habitar Pelotas" a possibilidade de patrimonialização destes elementos que constituem o território do Passo dos Negros, em suas diferentes temporalidades.

Desde 2016, o dossiê de patrimonialização vem sendo elaborado, colaborativamente com a comunidade. E vem respaldando uma disputa de narrativas sobre a cidade. Por um lado, tem-se a ideia de reforçar um território negro, de trabalhadores/as, que se vinculam à temporalidade da charqueada e do engenho valorizada oficialmente. A patrimonialização busca o reconhecimento do Passo enquanto lugar de referência das comunidades negras e sua inserção no processo de tombamento Conjunto Histórico de Pelotas. Trata-se de reconhecer, oficialmente, a presença negra na cidade. Outra narrativa, refere-se à antiguidade do habitar a localidade, pautada no direito à cidade, nos modos de vida diversos, que atrita com a narrativa de uma cidade formal dos planos diretores e dos empreendimentos imobiliários.

\section{Considerações Finais}

Os dois casos etnográficos nos remetem a processos de importantes de disputa pelo reconhecimento de práticas de trabalho, de formas de sociabilidade e de sentidos de pertencimento que se configuram na memória de grupos invisibilizados em seus territórios marginais. Essas narrativas não são facilmente reconhecidas como práticas, sociabilidades e saberes legítimos para estruturarem uma narrativa oficial sobre modos de habitar a cidade. Porém, por outro lado, essas mesmas narrativas (ou contra-narrativas) são pródigas em demonstrar os limites das narrativas oficiais, mostrando suas inconsistências e, especialmente, a sua incompletude, ou seja, que a produção da cidade é um processo constante e permeado pelas tensões da disputa dos diferentes grupos sociais pela possibilidade de nomear seus lugares de pertencimento.

As disputas em Pelotas acerca ao que é próprio para ser definido como Patrimônio expressa o desejo das pessoas reconhecerem o seu lugar e colocá-lo numa condição de centralidade, em que esse mesmo lugar com suas práticas, símbolos e sentidos definam-se como território legítimo, passível de ser reconhecido pelo outro como um espaço próprio da 
cidade. Nesta perspectiva, é interessante pensar a aproximação das noções de propriedade com a noção de patrimônio, como sugere Canani:

Assim, podemos dizer que a propriedade é um tipo de criação social, pois não é suficiente a existência de um objeto em si para que ele seja relevante para o grupo social, mas é relevante a atribuição de um valor, que é socialmente construído, e a existência de um conjunto de normas que regulam a sua circulação e permanência dentro do grupo, estabelecendo uma rede de relações entre pessoas. (CANANI, 2005, p. 165)

Podemos pensar então que o trabalho de reconhecimento de lugares, práticas e coisas que emergem em territórios de margem como patrimônio cultural é, ao mesmo tempo, um movimento que instiga uma extensão dos referenciais simbólicos que definem a vida própria à cidade e um recurso importante para dar visibilidade política aos grupos que pleiteiam seu reconhecimento como cidadãos. As tensões provocadas pelo reconhecimento da presença criativa dos negros e negras da tradição doceira de Pelotas, de início configurada como exclusivamente europeia, assim como os percalços produzidos na expansão dos condomínios fechados de classe-média alta na região do Passo dos Negros, em função das lutas por reconhecimento da representatividade histórica deste território, demonstram a força positiva da incorporação de populações marginalizadas nas disputas pela definição do conceito de Patrimônio Cultural.

A valorização e o reconhecimento produzidos por políticas de patrimonialização precedem de um trabalho de imaginação, no sentido da produção de uma imagem, de uma narrativa sobre este patrimônio. O Bem consagra esta imagem construída, portanto "sem imaginação, não há patrimônio" (TORNATORE, 2009/2010). A imagem pode ser pensada de diferentes formas para abarcar a heterogeneidade do viver a cidade, embora sempre vá envolver seleções de narrativas.

\title{
PELOTAS-RS BY ITS MARGINS: THE HERITAGE AS AN EXPRESSION OF THE MULTIPLE WAYS OF INHABITING THE CITY
}

\begin{abstract}
:
This paper purposes situate this work in the urban anthropology field that interprets the city not as an extern dimension to the residents, as a political and administrative unit, but to understand the city as a visual object, constituted by narrative disputes about their territories. To address this theme, we start from the tension between the normative cities through a reflection about its borders. Thinking about the the narratives agencies of subordinate from processes of cultural goods of patrimonialising in Pelotas/RS - Brazil. More than conforming to the official perspective on heritage, the text proposes a resignification of the concept. In Pelotas, different groups that takes for themselves the concept of heritage question those official narratives that disentangle the affluence during the beef jerky production period and invalidate the slavery past. Black communities start to claim for their presence in the
\end{abstract}


historical center constitution and others territories in the city, which has caused tensions in the use of these goods. In the end, the effects of this controversy influence definitions of the right to the city, which is no longer solely attributable to market pressures created by real estate expansion. This study allows us to perceive an important action in the definition of the city's territories, which goes through a dialectic between margin and center, a relevant dimension to define the very conception of urban center in dispute for ways of inhabiting the city.

Keywords: Cities; margins; cultural heritage.

\section{REFERÊNCIAS}

AGIER, M. Do direito à cidade ao fazer-cidade. O antropólogo, a margem e o centro. Mana 21(3):483-498, 2015.

AGUIAR, Marlise. Um olhar sobre o palimpsesto urbano: processo de formação e diferentes construções no tempo de um patrimônio arquitetônico às margens do Canal São Gonçalo (Pelotas/RS). 2009.

AIDAR, Gabriela. Museus e inclusão social In: Ciências \& Letras. Faculdade PortoAlegrense de Educação, Ciências e Letras. Porto Alegre, n. 31. 2002.

APPADURAI, Arjun. A vida social das coisas: as mercadorias sob uma perspectiva cultural. Niteroi, EdUFF, 2008.

APDP. Site da Associação dos Produtores de Doces de Pelotas. disponível em http://www.docesdepelotas.org.br/. acesso em set./2015.

CANANI, Aline. Herança, sacralidade e poder: sobre as diferentes categorias do patrimônio histórico e cultural no Brasil. Horizontes Antropológicos, Porto Alegre, ano 11, n. 23, p. 163-175, jan/jun 2005.

DE CERTEAU, Michel; LUCE, Giard; and PIERRE, Mayol. A invenção do cotidiano: morar, cozinhar. Vozes. 2008.

DE MENESES, Ulpiano. A Cidade Como Bem Cultural: áreas envoltórias e outros dilemas, equívocos e alcance da preservação do patrimônio ambiental urbano. Patrimônio: atualizando o debate. Rio de Janeiro: IPHAN, p. 31-53. 2006.

GUTIERREZ, Ester. Negros, charqueadas e olarias. Um estudo sobre o espaço pelotense. 1993. Diss. Dissertação (Mestrado em História) - Faculdade de História, Pontifícia Universidade Católica do Rio Grande do Sul. Porto Alegre, 1993.

INRC. Inventário Nacional de Referências Culturais - Produção de doces tradicionais pelotenses. Relatório Final. Coordenado por Flávia Rieth, F.et al. Vol.1 e Vol 2. Universidade Federal de Pelotas. Pelotas: Editora da UFPEL. 2008.

IPHAN. Parecer do Processo de Tombamento no 1512-T-03 - Conjunto Histórico de Pelotas, Estado do rio Grande do Sul. 2018a.

IPHAN. Parecer do Processo de Tombamento n⿳0 0145016835/2009-92 - Região doceira de Pelotas e Pelotas antiga, Estado do rio Grande do Sul. 2018b. 
KOSBY, Marilia. Aqui nós cultuamos todas as doçuras: a contribuição para a tradição doceira de Pelotas. Trabalho de conclusão (em Ciências Sociais), Instituto de Ciências Humanas, Universidade Federal de Pelotas. 2007.

LEFEBVRE, H. O direito à cidade. São Paulo: Centauro, 2001.

MAGNANI, J.G. Da periferia ao centro: trajetórias de pesquisa em Antropologia Urbana, São Paulo: Editora Terceiro Nome, 2012.

SAID, E. 1990. O orientalismo: o Oriente como invenção do Ocidente. São Paulo: Companhia das Letras, 1990.

\section{Sobre os autores:}

Francisco Pereira Neto possui graduação em História pela Universidade Federal do Rio Grande do Sul, mestrado em Antropologia Social pela Universidade Federal do Rio Grande do Sul e doutorado em Antropologia Social pela Universidade Federal do Rio Grande do Sul. Atualmente é professor adjunto na Universidade Federal de Pelotas. Tem experiência na área da antropologia, com ênfase na antropologia urbana e da religião. Endereço Eletrônico: francisco.fpneto@gmail.com

Flavia Rieth possui licenciatura e bacharelado em Ciências Sociais pela Universidade Federal do Rio Grande do Sul, mestrado em Antropologia Social pela Universidade Federal do Rio Grande do Sul e doutorado em Antropologia Social pela Universidade Federal do Rio Grande do Sul. Atualmente é professora associada da Universidade Federal de Pelotas. Tem experiência na área de Antropologia, com ênfase em Cultura e Patrimônio, Antropologia e Meio Ambiente, e Antropologia Urbana e Família e Parentesco. Endereço Eletrônico: riethuf@oul.com.br

Louise Alfonso possui Doutorado em Arqueologia pelo Museu de Arqueologia e Etnologia da Universidade de São Paulo, Mestrado em Antropologia Social pela Universidade Estadual de Campinas e Bacharelado em Turismo pela Pontifícia Universidade Católica de Campinas. Professora do Departamento de Antropologia e Arqueologia e do Programa de Pós Graduação em Antropologia da Universidade Federal de Pelotas. Tem se dedicado aos estudos voltados para as diversas compreensões da Cultura Material, Patrimônio e Sociedade sob uma perspectiva multidisciplinar, envolvendo reflexões da Arqueologia, Antropologia, Turismo, Sociomuseologia e da conservação. Endereço Eletrônico: louise_alfonso@yahoo.com.br 